QNueva Etinexaxia Revista Digital de OFilosofia ISSN 1850-3578 2013 - Vol. 8 - Número VIII - Resistencia, Chaco, Argentina. Pp. 91 - 107

\title{
La experiencia estética del arte contemporáneo.
}

\section{Algunos señalamientos antropológicos}

\author{
Saúl Mauricio Niveyro Linares \\ Universidad Nacional del Nordeste (Argentina)
}

Recibido: $19 / 07 / 2013$

Aceptado: 08/08/2013

\section{Resumen}

El siguiente trabajo aborda el tema la experiencia estética contemporánea y sus consecuencias antropológicas. Parte de dos preguntas: ¿Cuáles son las características del arte contemporáneo? y ¿es posible señalar algunos rasgos de la experiencia estética contemporánea? Ante esas problemáticas se propuso como hipótesis que la caracterización de la experiencia estética contemporánea puede desprenderse de algunos rasgos del arte denominado contemporáneo. Ambos develan problemas antropológicos que se intentarán señalizar desde el enfoque hermenéutico. Se plantea como objetivo primero, comprender e interpretar algunos rasgos del arte contemporáneo. Segundo, caracterizar la experiencia estética propia de la contemporaneidad, para luego deducir algunas consecuencias antropológicas.

La estructura del trabajo consta de presentación, primera parte donde se focaliza en los rasgos del arte contemporáneo. La segunda, se centra en la caracterización de la experiencia estética propia de la contemporaneidad, para luego deducir algunas consecuencias antropológicas.

Palabras clave: experiencia estética, hermenéutica, Antropología, Historia, arte.

\section{Abstract}

The following paper discusses the issue of contemporary aesthetic experience and its anthropological consequences. It starts from two questions: What are the characteristics of contemporary art? Is it possible to point out some features of the contemporary aesthetic experience? Given these problems it was suggested the hypotheses that the characterization of the contemporary aesthetic experience can be inferred from some traits of the so called contemporary art. Both questions reveal anthropological issues which we will try to signal 
QNueva Etinexaxia Revista Digital de OFilosofia ISSN 1850-3578 2013 - Vol. 8 - Número VIII - Resistencia, Chaco, Argentina. Pp. 91 - 107

from the hermeneutic approach. The aims were, first, to understand and interpret some features of the contemporary art and secondly, to characterize the aesthetic experience typical of contemporaneity, in order to deduce some anthropological consequences. The structure of the paper consists of an introduction - a first part which focuses on the features of contemporary art, and a second part focusing on the characterization of the aesthetic experience typical of contemporaneity, in order to deduce some anthropological consequences.

Keywords: aesthetic experience, hermeneutics, Anthropology, History, art. 
eNweva Etinesania Revista Digital de OFilosofia ISSN 1850-3578 2013 - Vol. 8 - Número VIII - Resistencia, Chaco, Argentina. Pp. 91 - 107

Son los espectadores

quienes hacen

la obra de arte.

Marcel Duchamp.

Este artículo pretende definir algunas características del arte contemporáneo y consecuentemente de su experiencia estética. Si bien no se trata de un tópico original, sí compete a una cuestión de arte contemporáneo no cerrada aún. Por lo tanto, el centro del trabajo estará dado por dos etapas. La primera, consistirá en comprender e interpretar algunos de sus rasgos. De esta caracterización se desprende la segunda etapa sobre la determinación de la experiencia estética, propia de la contemporaneidad, ${ }^{1}$ para luego deducir algunas consecuencias antropológicas. Por lo tanto, se mencionarán oportunamente algunas obras y autores representativos, a modo de prueba acerca de lo que se describe de las percepciones, sobre algunas obras.

Se identificaron dos problemas. ¿Cuáles son las características del arte contemporáneo? Y, a partir de ellas ¿es posible determinar algunos rasgos de la experiencia estética contemporánea? Se consideraron estas preguntas por las siguientes razones: en primer lugar, porque se está ante una nueva producción de arte que implica re - pensar el arte, después de la era del arte. ${ }^{2}$ En segundo lugar, porque re-pensar significaría, intentar al menos, caracterizar el fenómeno por estudiar. Y en la medida que se lo caracteriza, entonces se lo podrá definir. De esta manera, se lo podrá identificar. Este proceso es, en parte, un proceso semiótico. Es un especial recorte de su dimensión semántica que trata de otro más específico aún, denominado 'designación', es decir, el conjunto de las características definitorias del término en cuestión: 'la experiencia estética del arte contemporáneo'.

En tercer lugar, la caracterización del arte contemporáneo supone la problemática de la periodización de la misma, que sin duda requiere de una discusión y por ende, un estudio aparte. Lo cierto es que se trata de procesos y acontecimientos históricos muy complejos. No es el objetivo del artículo delimitar fechas ${ }^{3}$, sin embargo, al respecto se sigue la posición de

\footnotetext{
${ }^{1}$ El efecto de shock. Cf. OLIVERAS Elena. Estética. La cuestión del arte. Bs. As., Ariel, 2006, p.44.

2 Cf. DANTO Arthur C. Después del fin del arte. El arte contemporáneo y el linde de la historia. Barcelona, Paidós, 1999, p.26.

${ }^{3}$ Es una solución a los efectos de seguir con los objetivos propuestos.
} 
Danto que establece entre los años 1880 y 1960 el arte moderno, y entre 1949 y 1975, el periodo en que inicia el linde entre lo moderno y lo contemporáneo. ${ }^{4}$

Ante las dos problemáticas se propone una hipótesis, se afirma que la caracterización de la experiencia estética contemporánea, puede desprenderse de algunas de las particularidades del arte denominado contemporáneo.

El marco teórico de una investigación que pretende inquirir con profundidad, tiene el deber de validar el método ${ }^{5}$ con el que investigará. Por lo tanto, los objetivos en el presente apartado son, por un lado clarificar los supuestos teóricos de la hermenéutica filosófica ${ }^{6}$ desde dónde se interpretará la experiencia estética contemporánea, y por el otro, mostrar elementos teóricos del enfoque elegido.

Explicar de este modo, resguarda de las interpretaciones azarosas y arbitrarias. No obstante, es una frontera que el hermeneuta siempre debe cuidar metódicamente. Comprender en profundidad este apartado, significará estar bien ubicado en las lecturas posteriores que se hacen de la experiencia estética contemporánea, como así también, saberse partícipe de las interpretaciones que se realizan en el presente artículo; estar consciente de las mismas es posible, en virtud del acceso a los elementos teóricos-hermenéuticos, que aquí se presentan.

Si se pregunta ¿qué es la hermenéutica? la interrogación formulada, lleva directamente a tratar de clarificar el concepto. Si se pretende encontrar una delimitación única en un campo, a la vez antiguo y complejo, se caerá en grandes inconvenientes. Dada esa advertencia, es pertinente decidirse por un concepto ajustado al enfoque atinente a la propuesta y al trabajo que se pretende hacer. Para ello, se comenzará afirmando, que 'hermenéutica' es poder ponerse completamente a distancia en el acto interpretativo, implica tomar a la hermenéutica como un método. Esta acepción metódica del concepto, ofrece un criterio que permitirá clarificar las siguientes cuestiones: ¿qué se está buscando en la caracterización de algunos rasgos de la experiencia estética contemporánea?, ¿desde dónde interrogamos a los objetos

\footnotetext{
${ }^{4}$ Cf. DANTO Arthur C. Después del fin del arte, op. cit., pp.33 y ss. Y en su otro libro El abuso de la belleza. La estética y el concepto de arte. Barcelona, 2008, p.46, marca la obra Fontaine de Duchamp como disonante. Asimismo la profesora Dra. Elena Oliveras señaló el año 1917 con la obra de Marcel Duchamp. Fontaine. Ready - made, 1917. También en JIMÉNES José. Teoría del arte. Madrid, Tecnos Alianza, 2003, p. 48, el autor señala 1917 como el momento emergente de un nuevo proceso técnico que llevaría a un cambio en el modo de producción de los objetos artísticos. En las consecuencias antropológicas se asume una posición crítica al respecto.

${ }^{5}$ El método supone reglas de cómo hacer racionalmente algo, con un objeto determinado que tiene condiciones previas de inteligibilidad. Por esa razón en el artículo se pone el acento más en las reglas de un método que en los pasos del mismo.

${ }^{6}$ Se sigue el espíritu de la obra de GADAMER Hans-Georg. Verdad y Método. Salamanca, Sígueme, 2005, vol. I, II. 9. La historicidad de la comprensión como principio hermenéutico y II.11.3.b) La lógica de la pregunta y la respuesta.
} 
artísticos? Lo que en otras palabras podría preguntarse: ¿cuáles son los presupuestos con los que se interpretarán las pinturas? ¿Qué es lo que se interrogará sobre las mismas? ¿Qué aspectos relevantes permitirán definir el objeto de estudio sobre el que se indaga? Y por último, ¿cómo se lo interrogará?

Todas estas incógnitas permitirán clarificar el concepto hermenéutica como un instrumento, como un método. Pero asimismo, se adoptará otra acepción que se encuentra directamente vinculada con el presente enfoque. Definir a:

la Hermenéutica como arte de comprender ${ }^{7}$ y como el arte de evitar el mal entendido (...) Todos los contenidos están implícitos en esta afirmación negativa (...) El mal-entendido surge por sí mismo; la comprensión ha de ser querida y buscada en cada momento. ${ }^{8}$

Esta segunda acepción se eligió con el objetivo de desarrollar el aspecto de arte, propio del concepto hermenéutica. Conviene recordar que la palabra 'arte' proviene del griego techné y luego ese vocablo persistió en la palabra latina ars. Entonces, el concepto arte encierra, por un lado la idea de "hacer" y por el otro, de "producir" algo mediante determinados métodos. Es oportuno entonces, detenerse en esta definición, para realizar dos reflexiones sobre la misma.

En primer lugar, se reflexionará sobre la idea de 'hacer'. Ésta implica consecutivamente, ejercicio y habilidad. Esto es así cuando uno quiere adquirir una habilidad. Toda destreza consolidada requiere de hacer y hacerlo con cierta regularidad, con el objetivo de afianzarla. En efecto, el entrenamiento es el antecedente que contribuye a su construcción. Por otro lado, cabe aclarar que el ejercicio por el ejercicio mismo, cae en un hacer mecánico y por ende, no comprensivo. Es por ello que la habilidad requiere de previas comprensiones para poder hacerlo, como también de una finalidad. Así, termina construyéndose la habilidad, cuando uno comprende lo que hace, es decir, sabe por qué lo hace (su fundamento) y para qué lo hace (su finalidad). Estos dos elementos, se consolidan con la destreza construida a partir de los ejercicios que se hacen conscientemente. Así, el hacer, no es un hacer por el hacer mismo, sino con pre - comprensiones sobre el por qué y el para qué hacerlo. Entonces, el hacer precomprensivo, que precede a la habilidad, es un hacer inteligente.

En segundo lugar, es atinente detenerse a reflexionar acerca de la idea de "producir" algo mediante determinados métodos. Cuando uno hace inteligentemente alguna cosa, "crea", en sentido amplio, algo. Y lo hace a partir de determinadas reglas creadas y dispuestas previamente por la conciencia metódica. Es decir que aquella conciencia recuperó el saber de

\footnotetext{
${ }^{7}$ MACEIRAS Manuel y TREBOLLE Julio. La hermenéutica contemporánea. Madrid, Ediciones pedagógicas, 1995, p. 35.

${ }^{8}$ SCHLEIERMACHER, 1959, p.30, citado por MACEIRAS Manuel y TREBOLLE Julio, op. cit. p.31.
} 


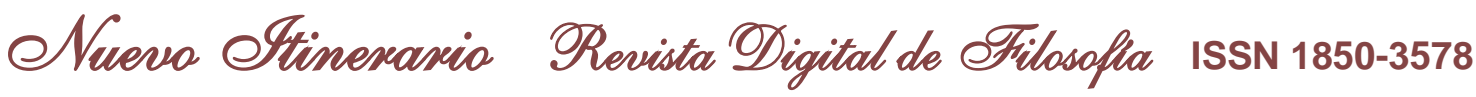
2013 - Vol. 8 - Número VIII - Resistencia, Chaco, Argentina. Pp. 91 - 107

los ejercicios y los ejercicios realizados, con previas comprensiones, construyeron la habilidad. La genealogía de la habilidad se sintetiza en forma de una capacidad aprendida, que puede desenvolverse por los pasos que se construyó. A partir de allí, se pueden fijar reglas. Y hablar de un conjunto de reglas, es hablar de "método". Además, cuando aquellas tienen determinados aspectos que los distinguen en su hacer, marcan así, el "modo". En otras palabras, el 'método' es un conjunto de reglas, su 'modo' está dado por las características que ellas le imprimen. Ahora bien, el sostener esas reglas requiere a la "conciencia teórica" como fundamento. El cómo llegar a hacerlo, requiere a su vez de fundamento a la "conciencia metódica" y el aplicarlas, para que la producción se haga efectiva, requiere por último, de la "conciencia práctica" como fundamento para la aplicación. Esta reflexión sirve para darse cuenta de que la 'hermenéutica' es arte y no puede dejar de serlo, ya que, el interpretar requiere de todo lo anteriormente expresado. $Y$ el concepto de arte, como una dimensión de la hermenéutica, es necesario para producir comprensión.

Para concluir, se afirma que el arte de la hermenéutica consistirá en evadir el mal-entendido que hace tiempo promueve obnubilaciones. Se sostiene además, que el mal entendido produce oscurecimiento por la prisión de los convencionalismos epocales. Esos aspectos son los que generalmente corresponden a rasgos, menos afortunados de nuestra cultura. El hecho de ser contemporáneos convierte a los intérpretes, casi ineludiblemente, en cautivos de los malos entendidos, ya que no es tarea sencilla, tomar distancia de esos convencionalismos. A partir de las simulaciones, que son las hacedoras de las tergiversaciones de significados, se está cuasi-expuesto a la posibilidad de ser mal juzgado por ellos. En este panorama poco alentador, se tratará de buscar sentidos de los productos artísticos que muestren los rasgos de la experiencia estética contemporánea. La "evidencia sentimental" será la luz en el derrotero del proceso de interpretar. En el caso de que se logre, se habrá aportado un grano de arena o un singular cambio, al amplio campo de las posibles exégesis, en el guión de nuestra cultura, en especial, al de sus características contemporáneas.

Para terminar, se afirma que la hermenéutica como método incluye un conjunto de reglas orientadas a la comprensión de sentido y la hermenéutica como arte, como techné de la interpretación, abarca un conjunto, tanto de capacidades como de habilidades para encontrar significados en la escritura.

Es pertinente puntualizar que la tarea de los filósofos es la de construir conceptos. ${ }^{9} \mathrm{Y}$ la de los filósofos del arte, es pensar el arte después del fin del arte, ${ }^{10}$ es comprender que la historia del

\footnotetext{
${ }^{9}$ Cf. DELEUZE Gilles y GUATTARI Félix. ¿Qué es la Filosofía?. Barcelona, Anagrama, 2001, p. 11.
} 


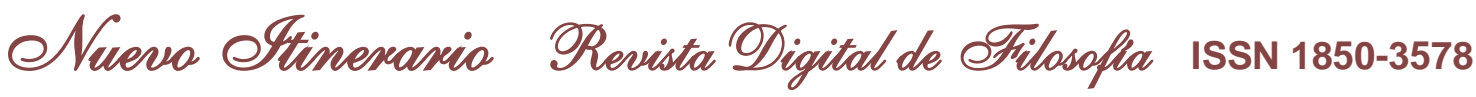
2013 - Vol. 8 - Número VIII - Resistencia, Chaco, Argentina. Pp. 91 - 107

auto-conocimiento es narrada por etapas y que éstas llevan progresivamente al conocimiento de quién es el hombre de modo que se regresa a la pregunta antropológica por excelencia. Puesto que cuando uno comprende quién es, entonces se conoce. Así se piensa la narración de la historia, que como tal es relatada y heredada por hombres reconocidos desde el poder, en etapas que conducen hacia el conocimiento de sí mismo. El fin de la historia, es simultáneamente, el fin de la narración. ${ }^{11}$ Su término acontece, cuando uno se conoce. Y ese día es el fin de la historia, ya que se conoce a sí mismo. Además, uno se da cuenta de que se conoce. Tal comprensión es lo que se denomina conciencia de la conciencia, entendida también como 'meta-conciencia'. En este sentido 'narrar' es pensar.

Ahora bien, cabe señalar dos distinciones. La primera es cuando a la historia se la vivió y se la cuenta personalmente. Sin duda que desde esta perspectiva, deberían cuestionarse puntos epistemológicos relativos al nivel de objetividad y subjetividad en los relatos. Y la segunda cuestión es también de orden epistemológico, pone el acento en cuando a la historia la cuenta otro, quien introduce intereses, modos de relatar, hitos o procesos históricos, omisiones, elementos materiales para la reconstrucción de los hechos: monumentos, documentos escritos, testigos oculares. En este trabajo se adoptará el siguiente punto de vista: la práctica investigativa en el modo de tratar estos elementos, conformará un tipo de historia. Muchos, como ocurrió en la modernidad, sentían fe en las grandes narrativas. Curiosamente, había un elemento irracional en el proceso gnoseológico: "la fe", en un periodo que se suponía racional. Se entiende por 'la muerte del arte' una narrativa que ha finalizado dentro de la historia del arte $^{12}$ lo que no significa que no habría más arte, sino que no hay fe en las grandes narrativas. ${ }^{13}$ Pero sí puede haber un arte denominado pos-histórico.

Se entiende por 'historia' la historia escrita por aquellos que están legitimados y sostenidos por el poder. Se entiende por 'historia oficial' aquella que es relatada por las instituciones oficiales y por los agentes que cumplen funciones en las mismas, por lo tanto, están

${ }^{10}$ DANTO Arthur C. Después del fin del arte, op. cit., p. 26.

${ }^{11}$ En el orden político-militar se puede tomar como ejemplo del muro de Berlín que dividió la República Federal Alemana de la República Democrática Alemana. Como toda narrativa tiene etapas: 1- la construcción del muro, (comienzo de la historia) 2- la defensa de sostener aquello que se construyó, (desarrollo de la historia) y 3 - la caída del muro, (fin de la historia). Es una gran narrativa política-militar que dividió Alemania en dos. Esta narrativa a su vez, es relatada de una manera por los Alemanes de la República Federal Alemana, y de otra por los alemanes de la República Democrática. Esa gran narrativa condicionaba fácticamente la historia de quienes forzosamente estaban allí. Contiene otras narrativas relevantes de aquellos que pasaron el muro. Sin embargo, tiene su fin.

${ }^{12}$ Cf. DANTO Arthur C. Después del fin del arte, op. cit., p.26.

${ }^{13}$ Por grandes relatos se entienda a: la dialéctica del espíritu de Hegel; la hermenéutica del sentido de Gadamer; la emancipación del sujeto razonante Descartes, Kant, Husserl; la emancipación del sujeto trabajador Marx; cf. LYOTART Jean-François. La condición postmoderna. Informe sobre el saber. Madrid, Cátedra, 1987, p. 9. 
Q Nueva Etinexaxio Revista Digital de OFilosofla ISSN 1850-3578 2013 - Vol. 8 - Número VIII - Resistencia, Chaco, Argentina. Pp. 91 - 107

legalizados, es decir: están instituidos. A ésa, se opone una 'historia no oficial', no legalizada y por ende, no instituida. Contiene a su vez las historias de otros: de los no reconocidos, de los desaparecidos, de los que son laterales, oblicuas, de los marginales, de los pobres, de los docentes, de los miserables, de los indigentes y de los indignados. Son historias igualmente sólo que subjetivas y adyacentes. Es decir, tienen sus narraciones que contar, que relatar, sólo que como algunos de ellos no saben escribir, no entran en la historia y por ende, son excluidos ya que según la versión oficial, la historia comienza con la escritura, con ella la historiografía, historia escrita. Lo que significa, que toda historia que no puede ser escrita, para la posteridad no será historia menos aún si es que no se conservó por tradición oral, tradición que no tiene la garantía estable de la escritura. Aquellas historias que no pueden ser escritas, por efectos de la marginación, son historias perdidas y su narración concluye paradójicamente antes de haber comenzado. En ese sentido, el arte contemporáneo aparece contado por los filósofos que escriben la historia oficial, aún en una etapa pos-histórica, donde el arte no se basa en grandes narrativas, con una tendencia a centrarse en Estados Unidos y Europa. Ésta es, si se quiere, una crítica a la crítica oficial. Aquí, en Latinoamérica, en Argentina, en el Chaco hay pintores que son marginales, porque no son reconocidos por la institución del arte internacional y quienes lo analizamos, también somos marginales. ${ }^{14}$ Ésta es la razón de haber optado por el método hermenéutico, el que permite, por medio del proceso de comprensión, interpretar al otro que está fuera de la historia oficial y que pese a ello, puede su arte estar en el momento poshistórico. Una vez puntualizada la posición respecto del concepto de historia, es oportuno clarificar cómo se entiende el concepto de 'arte moderno'. En su sentido simplemente temporal significa "lo más reciente" ${ }^{15}$ Otra acepción dice: 'Moderno' marca la diferencia entre el ahora y el antes ${ }^{16}$, como así también puede significar un estilo y un periodo ${ }^{17}$. Seguidamente, por 'arte contemporáneo' se entiende:

lo que está sucediendo ahora: el arte contemporáneo sería el arte producido por nuestros contemporáneos (...) el arte contemporáneo ha pasado a significar arte producido con una determinada estructura de producción nunca visto antes, creo, en toda la historia del arte. ${ }^{18}$

\footnotetext{
${ }^{14}$ Esto no significa una victimización de la posición, ni hacer uso de la misma para justificarse, sólo que se es consciente del lugar que se ocupa.

${ }^{15}$ DANTO Arthur C. Después del fin del arte, op. cit., 32.

${ }^{16} \mathrm{Cf}$. ibid.

${ }^{17}$ Cf. DANTO Arthur C. Después del fin del arte, op. cit., 32.

${ }^{18}$ Ibid.
} 
Ante la pregunta ¿con qué ojos ${ }^{19}$ se estará mirando la obra de arte contemporánea? Se intentará mirar con ojos críticos y con la mirada de público de arte. ${ }^{20}$ Asumir una mirada desde esta perspectiva, requiere conjuntamente con la conciencia metódica propia de la hermenéutica filosófica, ser consciente de las limitaciones, las cuales se enumeran a continuación.

Primer supuesto, indica que tanto el 'definir' como el 'caracterizar' son requerimientos intelectuales propios de la modernidad. Son procedimientos que extraen su modelo de la lógica aristotélica basada en el principio de identidad: A es idéntico a A. Si se considera la dinámica del cuadrado de oposición, se observa que si $A$ es verdadero, entonces $O$, su contradictoria, no puede serlo. Necesariamente será falso. Esto ocurre en el orden tanto lógico como ontológico, porque la dinámica de esa lógica se basa en el principio de identidad. ${ }^{21}$ Por lo tanto, si en este trabajo se pretende definir y caracterizar, se está tratando de connotar el objeto de estudio, es decir, se tratará de darle una identidad. Y se reconoce en esta investigación a uno de los objetivos de la trasnochada modernidad, devenida de la antigua dinámica, como así también que convendría cambiar la lógica y su dinámica para abordar el tema desde un punto de vista que no sea el de la modernidad, sus procedimientos de identificación y caracterización. ${ }^{22}$ En otras palabras, se estará definiendo y caracterizando lo contemporáneo con medios intelectuales propios de la modernidad. En principio, se lo considera válido hasta tanto se creen otros procedimientos contemporáneos ${ }^{23}$ para comprender e interpretar el arte emergente y sus consecuencias antropológicas.

Segundo supuesto, que señala la conciencia de un límite. La 'historia' es historia desde que apareció la escritura. Es decir que le debe su nacimiento a la escritura. Y la disciplina histórica depende, como conditio sine cuanon, de alguien que escriba la historia como resultado de la comprensión e interpretación de acontecimientos históricos, procesos históricos,

19 BOZAL Valeriano, BOZAL Valeriano. Notas sobre la experiencia estética. A propósito de algunos tópicos. En: Imágenes de la violencia en el arte contemporáneo. Madrid, La bolsa de la medusa, 2005., p. 20.

${ }^{20}$ Cf. OLIVERAS Elena. Cuestiones de arte contemporáneo. Hacia un nuevo espectador en el siglo XXI. Bs. As., Emecé, 2009, cap. V, donde trata en profundidad la diferencia entre los nuevos espectadores. Cabe señalar que si bien en partes inicia su discusión sobre la problemática con la obra de BALLO Guido. Occhio Critico. II nuovo sistema per vedere l'arte. Milano, Longanesi, 1966, aclara que Ballo distingue las diferentes conductas ante la obras de arte, pero no lo hace ante la obra conceptual, porque el libro de Guido coincide con la aparición del mismo.

${ }^{21}$ Y se basa también en la lógica de la dominación, expresada en las subalternas.

${ }^{22}$ Cabe agregar también los procesos de subordinación y por ende de dominación.

23 Por supuesto que no se niegan todos los aportes que están haciendo en este sentido, todos los teóricos de arte que se dedican a estas cuestiones. 


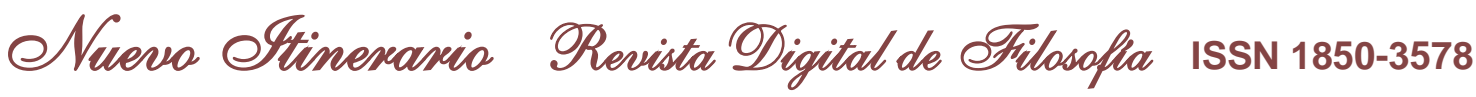
2013 - Vol. 8 - Número VIII - Resistencia, Chaco, Argentina. Pp. 91 - 107

monumentos y documentos escritos. Es decir que 'historia' es una historia escrita. Por lo tanto, la escritura depende de alguien y la historia depende de la escritura.

Tercer supuesto, muestra que la estética como disciplina debe dar cuenta de las condiciones de producción y validación del conocimiento estético. ${ }^{24}$ Por este motivo, dicamos una parte, si se quiere extensa, para dar cuenta de ello. ${ }^{25}$

La sola enumeración de las características del arte contemporáneo representaría unas veinte carillas como mínimo, indagación que se sigue realizando. Sin embargo, a los efectos de las formalidades del presente artículo, se seleccionaran unas pocas, de las cuales no se dirán que son las más relevantes aunque lo sean, porque 'relevante' también es un criterio que requiere comprensión e interpretación. Se coincide con Danto en que lo

«contemporáneo» ha llegado a designar algo más que simplemente el arte del momento presente. En mi opinión designa menos un periodo que lo que pasa después terminados los periodos de una narrativa maestra del arte y menos aún un estilo de arte que un estilo de utilizar estilos. ${ }^{26}$

Y también se acuerda con el autor en que:

lo contemporáneo es, desde cierta perspectiva, un periodo de información desordenada, una condición perfecta de entropía estética, equiparable a un periodo de una casi perfecta libertad. Hoy ya no existe más ese linde de la historia. Todo está permitido. ${ }^{27}$

A partir de estas significaciones sobre qué es lo contemporáneo como periodo dentro de la historia, se señalan algunas características del arte contemporáneo sin pretensiones de agotarlas. Primero, el arte correspondiente a este momento es de gran productividad experimental, ${ }^{28}$ que no tiene ninguna narrativa en qué basarse. ${ }^{29}$ Segundo, cualquier $\operatorname{cosa}^{30}$

\footnotetext{
${ }^{24}$ Caso contrario se estaría a la deriva como ya lo manifestara Theodor W. Adorno. Cf. Su Teoría Estética. Madrid, Akal, 2004, pp. 441 y ss.

25 En ese sentido, se siguen utilizando herramientas modernas para analizar fenómenos contemporáneos.

${ }^{26}$ DANTO Arthur C. Después del fin del arte, op. cit., p.32.

${ }^{27}$ DANTO Arthur C. Después del fin del arte, op. cit., p.34.

${ }^{28}$ Como ejemplo puede observarse la instalación de Ricardo Basbaum. ¿Te gustaría participar de una experiencia artística? Instalación interactiva. Estructura de acero pintado, malla metálica, colchones, almohadones, alfombra, ocho monitores, ocho circuitos cerrados de TV, dos reproductores de DVD, dos
} 


\section{Pweve Etinexaxia Revista Digital de OFilosofia ISSN 1850-3578}

2013 - Vol. 8 - Número VIII - Resistencia, Chaco, Argentina. Pp. 91 - 107

puede ser obra de arte, ${ }^{31}$ en el periodo denominado arte contemporáneo. Tercero, los artistas presionan los límites ${ }^{32}$ y después de los límites. ${ }^{33}$ Cuarto, con la filosofía en el arte, desaparece lo visual. No es necesaria la existencia de un objeto bello, ni siquiera la existencia de un objeto, $^{34}$ para que exista arte. Quinto, el arte contemporáneo no es crítico de la sociedad de consumo, ${ }^{35}$ es funcional a esa sociedad. ${ }^{36}$ Sexto, el arte contemporáneo busca el revuelo y el escándalo. ${ }^{37}$ Desea llamar la atención, ${ }^{38}$ cobrando así un sentido, si se quiere adolescente. ${ }^{39}$ Séptimo, nuestra sociedad premia y admite las esculturas propuestas por Hirst, ${ }^{40}$ por otro lado, no se conforma con hombres que denotan estar radicalmente desorientados. Octavo, el arte contemporáneo muestra su condición segmentada, desarticulada ${ }^{41}$ y flotante. ${ }^{42}$ Noveno, muchos de los procesos de producción del arte contemporáneo provocan repugnancia y desconcierto. ${ }^{43} \mathrm{Y}$ por último, décimo, el arte contemporáneo no tiene límites, en éste hay una ruptura de límites. ${ }^{44}$

A partir de estos rasgos de la contemporaneidad del arte, se desprenden las siguientes características de la experiencia estética.

En primer lugar, 'la experiencia estética contemporánea' es si se quiere, efecto de las exigencias temporales de la época caracterizada. Y se diferencia de la 'experiencia estética moderna' puesto que ésta ha estado referida a objetos naturales, bellos, que provocaban goce o placer estético. ${ }^{45}$ Sin embargo, en el modo de ser contemporáneo: "Tener una experiencia es

computadoras, dos videograbadoras, objeto de acero pintado de blanco de $125 \times 80 \times 18 \mathrm{~cm}$, documenta 12, Kassel, 2007.

${ }^{29}$ Cf. DANTO Arthur C. Después del fin del arte, op. cit., p.35.

${ }^{30}$ Como ejemplo puede observarse Marcel Duchamp. Portabotellas. Escurridor de botellas de hierro galvanizado $50 \mathrm{~cm}$ de altura $\times 33$ de diámetro, 1914 .

${ }^{31}$ Ibid.

${ }^{32}$ Como ejemplos pueden observarse las plastinaciones hechas por Gunther von Hagens

${ }^{33}$ Cf. DANTO Arthur C. Después del fin del arte, op. cit., p.36.

${ }^{34}$ Cf. DANTO Arthur C. Después del fin del arte, op. cit., p.38.

${ }^{35}$ Obsérvese algunas obras de Barbara Kruger

${ }^{36}$ Cf. JIMÉNES José, op. cit., p. 26.

${ }^{37}$ Cf. JIMÉNES José, op. cit., p. 40, también caracteriza del mismo modo ${ }^{37}$ BOZAL Valeriano. Notas sobre la experiencia estética. A propósito de algunos tópicos. En: Imágenes de la violencia en el arte contemporáneo. Madrid, La bolsa de la medusa, 2005, p. 15.

${ }^{38}$ Obsérvese un ejemplo en la obra de Martín Di Girolamo. Racquel Darrian. Óleo sobre tela, $150 \mathrm{x}$ $120 \mathrm{~cm}, 1982$.

${ }^{39}$ Cf. JIMÉNES José, op. cit., p. 36.

${ }^{40}$ Cf. JIMÉNES José, op. cit., pp. 40 - 41.

${ }^{41}$ Obsérvese un claro ejemplo de desarticulación la obra de Framk Gehry. Museo Guggenheim. Bilbao, inaugurado en 1977.

${ }^{42}$ Cf. JIMÉNES José, op. cit., p. 41.

${ }^{43}$ Cf. JIMÉNES José, op. cit., pp. $42-44$, en especial tanto el relato de Hirst como el caso de Piero Manzoni y su Merde d' Artiste $N^{\circ} 47$ (1961).

${ }^{44}$ Cf. JIMÉNES José, op. cit., p. 39.

${ }^{45}$ Cf. BOZAL Valeriano, op. cit. p. 13. 


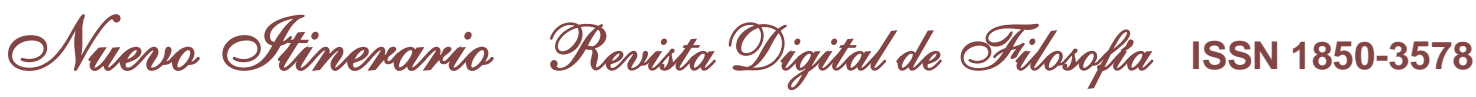
2013 - Vol. 8 - Número VIII - Resistencia, Chaco, Argentina. Pp. 91 - 107

hacer un recorte indiferenciado con un principio y un fin; de allí aquello que la caracteriza sea la completud. Nada más alejado de una experiencia que el estado anestésico en el que todo fluye indiferenciadamente." ${ }^{46}$

En segundo lugar, la experiencia estética contemporánea no está referida necesariamente a objetos naturales, ni bellos. Y no necesariamente provocan goce estético. Muy por el contrario. En la experiencia contemporánea, hay una frecuente experiencia de desagrado. En tercer lugar, es una experiencia contaminada. ${ }^{47} \mathrm{Se}$ elimina el límite entre personas de buen 0 mal gusto. ${ }^{48} \mathrm{El}$ mal gusto puede enriquecer. ${ }^{49}$ En cuarto lugar, se coincide con Bozal cuando afirma que

la experiencia estética se produce en el curso del tiempo, sufre altibajos, no siempre es igual, no posee el mismo nivel o intensidad en todas las ocasiones, acontece en tiempos y con objetos diversos. Puede disminuir sin llegar a desaparecer, aumentar sin «romperse»: su perfil es de los dientes de sierra, hay experiencias en las cumbres y en los valles. ${ }^{50}$

Por último, en quinto lugar, el 'paroxismo' es una característica frecuente. Conviene detenerse en su definición lexicográfica. ${ }^{51}$ Paroxismo. (Del gr. Paroxysmós, de paroxinō) definido desde el punto de vista de la Medicina, como el acceso violento de una enfermedad. Otra acepción la entiende como exaltación extrema de los afectos y las pasiones. Este concepto ayuda a comprender dimensiones de la experiencia estética contemporánea, ya que se la vive como un paroxismo, porque asistimos a una época en la que somos pacientes (sufridos, violentos y violentados, resignados, conformes y conformados). Además, porque hemos perdido el sentido de nuestras vidas y por eso estamos ultra-cansados, des-vitalizados. Lo trágico de ese padecimiento, es que no tenemos la capacidad de parar. La pérdida del sentido y sus efectos es tan fuerte, que nos lanza violentamente a la parálisis. Y por esa razón, nuevamente se atenderá a la definición lexicográfica de 'Pasión'. Del (lat. Passio, ōnem) Acción de padecer. Dolor, sufrimiento. Tormento y muerte. Lo contrario a la acción. Aquí, nuevamente aparece la

\footnotetext{
${ }^{46}$ OLIVERAS Elena. Cuestiones de arte contemporáneo, op. cit, p.139.

${ }^{47}$ Cf. BOZAL Valeriano, op. cit, p. 15.

${ }^{48}$ Cf. BOZAL Valeriano, op. cit, p. 16-17.

${ }^{49}$ Cf. BOZAL Valeriano, op. cit, p. 17-18.

${ }^{50}$ BOZAL Valeriano, op. cit, p.20.

51 Para profundizar sobre este uso, a la vez lingüístico y recurso metodológico auxiliar, cf. ASTI VERA Carlos y AMBROSINI Cristina. Estructura y procesos. Temas de Epistemología. Bs. As., Educando, 2005, pp. 31- 35.
} 


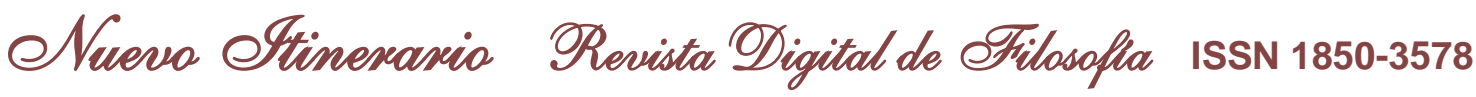
2013 - Vol. 8 - Número VIII - Resistencia, Chaco, Argentina. Pp. 91 - 107

razón de por qué somos pacientes. Y lo somos porque sufrimos la acción. Si no hay acción no hay arte, en su lugar hay una fuerte expresión de desesperación producto del dolor, del sufrimiento y del tormento. Es un estado pasivo del sujeto, perturbación o afecto desordenado del ánimo. Aquí puede hallarse el estrato antropológico más profundo de la experiencia contemporánea. 'Pasión' también significa, emoción intensa. Vehemente afición o inclinación excesiva de una persona a otra. Apetito, deseo de una cosa, o afición vehemente de ella. Tristeza, depresión, abatimiento.

Es difícil aceptar la pérdida del sentido y en consecuencia aceptar que no hay narración por contar. No hay conocimiento por descubrir, porque todo lo vivido, lo vivimos tan rápido y tan superficial que nada nos satisface. La ciudad propone soledad, un problema antropológico propio de la modernidad y que en la contemporaneidad se manifiesta hasta el paroxismo. El desgarro, el frenesí a cualquier precio. Algo similar acontece con la presencia de marcos en algunas obras contemporáneas. El 'marco' es la perfecta excusa para mostrar que supuestamente todo está ordenado, cuando por dentro la sensación de perdición no se detiene. No hay diferencias de espacios, porque no hay continente ni contenido. Y no lo hay, porque hay una disolución de los límites. Lo lacerantemente cierto es que el resultado es la desagradable parálisis de no hacer nada con nuestras vidas. Y por esa razón, ser nadie. Todo ello produce un shock emocional, sobre todo, al darse cuenta de que uno es un ser humano y aún así no se es consciente de que este modo de vida nos conduce al embargo del tiempo vital.

A partir de allí, todas las narraciones vividas terminaron consumidas por la irresolución de la ciega creencia en mega relatos que mostraron su costado más crudo, como así también su lado más desgarrador. Las narraciones eran sólo simulacros. Y esto conduce a una actuación con parámetros ficcionales, que producen tristeza, soledad, ira, muerte, una actitud pasiva respecto de sí misma. Esa actitud refuerza el paroxismo de la experiencia estética del siglo XXI. Se pretenden resolver vertiginosamente las situaciones conflictivas. Ese modo de resolver muestra las consecuencias de una excedida y trasnochada forma de ser propia del hombre, en la que sus resultados sólo producen desconcierto y desagrado.

Se concluye que el marco teórico intenta ser pertinente para los tiempos tardomodernos ${ }^{52}$ puesto que la ciencia no considera relevantes los enunciados de primer nivel, ${ }^{53}$ lo cual plantea serios problemas para la Estética como disciplina.

\footnotetext{
52 OLIVERAS Elena. Estética, op. cit,, p.50.

53 Cf. KLIMOVSKY Gregorio. Las desventuras del conocimiento científico. Una introducción a la epistemología. Bs. As., a-z editora, 2005, p. 73.
} 


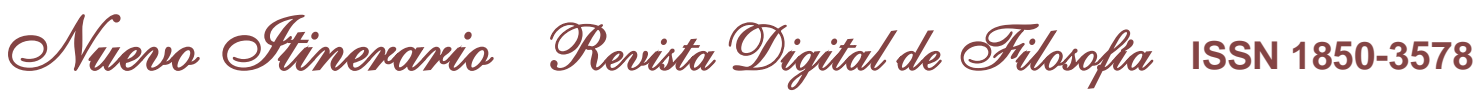
2013 - Vol. 8 - Número VIII - Resistencia, Chaco, Argentina. Pp. 91 - 107

Inicialmente se plantearon dos interrogantes, el primero de ellos apuntaba a cuáles son las características del arte contemporáneo. Y el segundo se centró en si ¿es posible caracterizar algunos rasgos de la experiencia estética contemporánea? Ante estos interrogantes se propuso una respuesta a título de hipótesis en donde se afirmó que la caracterización de la experiencia estética contemporáneas puede desprenderse de algunos rasgos de las características del arte denominado contemporáneo. Para ello se propusieron dos objetivos: el primero, definir algunas características del arte contemporáneo y segundo, consecuentemente identificar algunos rasgos la experiencia estética contemporánea. A modo de prueba de la hipótesis se propuso dar algunos ejemplos en los que se pudieran observar los rasgos descriptos.

En cuanto al primer interrogante, se decidió por las características expuestas, observando que el arte contemporáneo es notablemente complejo, diferente y que cada rasgo es un modo de acceso al arte que contiene lo universal en lo singular. ${ }^{54}$ En cuanto al segundo interrogante se pudieron deducir esos atributos en los productos artísticos de algunas obras contemporáneas observadas. Por lo tanto, la hipótesis que afirma que de la caracterización de la experiencia estética contemporánea, pueden desprenderse de algunos rasgos de las características del arte denominado contemporáneo, se confirmaba en cada uno de los casos en los que se percibía, uno o más de los rasgos contemporáneos en las pinturas a las que se hace referencia al pie.

Hay artistas que pueden ser pos-históricos por los aspectos privativos encontrados en sus obras. Se llega a ese conocimiento por otra vía igualmente legítima, aunque tal vez no legitimada por la historia oficial. Pero sí validada por procedimientos hermenéuticos. Y fueron estos los que permitieron cumplir con los objetivos. Utilizando la secuencia de presentar el tema, formular los problemas, fundamentar por qué estos interrogantes constituyen un problema. Luego se ensayó una respuesta como hipótesis de trabajo. Posteriormente, se delinearon las premisas fundamentales del enfoque para cumplir con los objetivos propuestos, como asimismo se precisó desde qué tipo de perspectiva se mirarían los objetos artísticos. Inmediatamente se procedió a la identificación de las características del arte contemporáneo y su consecuente experiencia estética. Por último, se propusieron las descripciones de las percepciones de las obras contemporáneas señaladas en las referencias, con el fin de poner a prueba la hipótesis sostenida, cuyo resultado es la confirmación de la misma. Por esas razones, se dice que esta confirmación está validada por una instancia tanto conceptual como metódica. La primera, por haber explicitado los conceptos principales con los que abordamos

\footnotetext{
${ }^{54}$ Cf. OLIVERAS Elena. Estética, op. cit. p.50.
} 
Pverea Etinexaxio Revista Digital de OFilosofla ISSN 1850-3578 2013 - Vol. 8 - Número VIII - Resistencia, Chaco, Argentina. Pp. 91 - 107

la temática y haber seleccionado de modo preciso las características del arte contemporáneo que son de suyo, para luego -a partir de observaciones pertinentes- comprender consecuentemente, la experiencia estética denominada contemporánea.

Toda conclusión agrega algo de conocimiento que excede el contenido de las premisas de las cuales se partieron. Por ello, se deja constancia de problemas pendientes que se reconocen como propios del arte contemporáneo.

El primero de ellos consiste en una tendencia a la dogmatización del discurso en los críticos de arte actuales, puesto que el discurso de estos críticos contemporáneos emplean, deja fuera a todos los países del tercer mundo, ${ }^{55}$ ya que lo que ellos describen es de alguna manera, desde un punto de vista que se está proponiendo, efecto de la revolución industrial agraria y tecnológica que tuvo lugar en Inglaterra en 1750 , en el periodo de la modernidad. A partir de allí, viene construyéndose, por medio de complejos mecanismos psicológicos, sociales, políticos y culturales, la cultura de masas. Siendo la contemporaneidad cierta continuidad y reconfiguración de los procesos emprendidos en aquel momento. Este modo de ver, muestra la base de lo que podría denominarse el cambio en la forma de producir los objetos artísticos en la época contemporánea.

Segundo, en cuanto a las limitaciones, se observa que la estética debe desarrollar un corpus teórico que permita una validación epistemológica de la misma. ${ }^{56}$

Porque en primer lugar y en sentido amplio, es un arte que está sucediendo ahora. En segundo lugar, porque en sentido estricto, su modo de producción corresponde a la diferencia específica con el arte moderno. En tercer lugar, porque sus manifestaciones rompen con el periodo clásico anterior. En cuarto lugar, porque en sus exposiciones no se usan criterios históricos ni formales. En quinto y último lugar, asistimos a un periodo experimental puesto que las obras no tienen ninguna narrativa de base.

El tercero de los problemas del que se pretende dejar constancia es la existencia del marco en algunas obras contemporáneas. Ante esa problemática, se hace la siguiente reflexión: 'El marco' es una característica de la pintura moderna, que tenía la función de delimitar lo real de lo irreal, por lo tanto, contribuye a no salirse de los límites. En otras palabras, la sin-razón del arte puede expresarse dentro de los límites que la razón impone. Paradójico pero aceptable. Y ¿cómo es posible que en una pintura contemporánea aparezca el marco?, ¿qué se comprende de la existencia del marco respecto de los objetos que contiene? El marco en la obra es tan

\footnotetext{
55 Excepto, la crítica de arte Elena Oliveras que interpreta las obras de las diferentes regiones de Latinoamérica.

${ }^{56}$ Como ciencia de lo extremadamente singular. Cf. OLIVERAS Elena. Estética, op. cit., p.50-51.
} 
sólo la excusa que esconde la pérdida de lo real. Tan sólo se lo utiliza para no salirse de las convencionales formas y es parte de una convención ponerlos. Se trata de una pintura a la que le cuesta, si es lícito hablar de ese modo, reconocer su identidad. Reconocer que tales límites son una ficción, que todo está desbordado, trasgredido, violentado y violado. Y que la apariencia de los límites ya no se puede sostener. Lo que es aún peor, es la pérdida de la realidad hiriente. Como dice Jean Baudrillard: "La imposibilidad de escenificar la ilusión es del mismo tipo que la imposibilidad de rescatar un nivel absoluto de realidad. La ilusión ya no es posible porque la realidad tampoco lo es." ${ }^{57}$

De estas problemáticas se deducen que el problema de fondo es, en definitiva, un problema antropológico. A continuación se señalan algunos.

El primer problema antropológico es que el ser humano está atrapado en la ciudad. Así los hombres se encuentran fragmentados por las grandes urbes. Anestesiados por estímulos y demandas caóticas, tanto interiores como exteriores del hogar desintegrado. Tanto psíquicas como extra-psíquicas. ${ }^{58}$ Todo se vuelve más caótico aún, porque se asiste a la trasnochada caída de la ilusión que sembró la revolución industrial. Poderosamente se tiende a la saturación de introyectos, pretendiendo cumplir como autónomas anestesiados, en el ámbito de nuestro propio ser. Los seres humanos aspiran a sostener una mirada central como una reacción refleja que denota tan sólo el final. Los rostros están petrificados por la pasión de la codicia, los apetitos carnales, la insoportable soledad, la desesperación acallada, la ansiedad y el pánico de una mirada dispersa, por lo tanto, confusa. El cansancio todo lo cubre. Algunos seres humanos solicitan ayudas que nunca llegan. Porque estamos solos en la ciudad enfurecida. Hay miradas que expresan la pasión de la ira. Estar atrapados en la ciudad, es estar atrapados y anestesiados por pasiones incontrolables. Cumpliendo el deseo de otros que acumulan capital cuando uno se siente encerrado en la penumbra de su soledad. Una soledad que hastía, ya que supuestamente en la ciudad hay muchas personas, pero todas ellas están tan atrapadas como nosotros. Y cuando se las necesitan nunca están. Con frecuencia el golpe con esa cruda realidad, en la que muchos ciudadanos te dicen: "estamos con vos". Pero la experiencia estética confirma lo contrario.

El segundo problema antropológico el ya conocido problema del otro. El caso de los oriundos que vivían en América cuando los otros (europeos) trajeron sus narraciones, enfermedades, engaños y una desenfrenada sed de poder y riquezas, que hoy están institucionalizados. Esta

\footnotetext{
${ }^{57}$ BAUDRILLARD Jean. Cultura y Simulacro. La precesión de los simulacros. Barcelona, Kairós, 1978, p.47.

${ }^{58} \mathrm{Cf}$. El concepto de anestésico desarrollado por OLIVERAS Elena. Cuestiones de arte contemporáneo, op. cit., 139-140.
} 
Pwerva Ettinenaxia Revista Digital de Prilosofia ISSN 1850-3578 2013 - Vol. 8 - Número VIII - Resistencia, Chaco, Argentina. Pp. 91 - 107

es la otra historia que está fuera de la historia de algunos críticos de arte, ${ }^{59}$ ya que muchas no fueron escritas, puesto que no pertenecieron a las narraciones europeas ni a la de los Estados Unidos. Si se observan los hitos históricos de la historia moderna y contemporánea en el arte, no se encuentran los pueblos originarios de América. Ellos tenían su canto, ${ }^{60}$ sus tradiciones orales, que jamás fueron comprendidos ni escuchados. Hoy luchan por recuperar tierras que fueron suyas y aún les pertenecen. Hoy temen por su identidad. La ambición de aquel que no tiene la piel color café, sigue desmontando, envenenando con agro tóxicos en aras de satisfacer su desmedida ambición. Respetar la historia del otro es muy difícil, especialmente para el hombre de color blanco y pelos dorados. Los hombres de acá adoraban el brillante sol, el verde de la naturaleza, la algarroba, pero no son europeos, ni de los Estados Unidos. Sabían de respeto hacia la fuente de la vida. Si tuvieron o no grandes narraciones ¿de qué sirvieron Auschwitz, el muro de Berlín, la muralla China? Nada de eso aconteció por relatos indígenas. Es el curso de la historia oficial, la otra historia no cuenta, no es institucional, está fuera. La otra historia ¿tendrá carácter de pos-histórica? ¿Será pre-histórica? ¿Alguien tendrá en cuenta estas preguntas? ¿Interesará?

\footnotetext{
${ }^{59}$ En la presentación se desarrolló la posición respecto del concepto de historia que se sostiene y la lógica de la dominación, sustentada en la lógica formal del cuadrado de oposición.

${ }^{60}$ Hoy, muchos pueblos originarios están auto recuperándose, tratando de decir y mostrarse desde sí mismos. Un claro ejemplo es el film La nación oculta llevada a cabo dentro del marco del 4to festival de cine de los pueblos indígenas, en Resistencia, jueves 25 de agosto de 2011.
} 